\title{
Effect of Different Budding Methods and Times on Grafting Success of Walnut
}

\author{
Zia Nosrati ${ }^{1^{*}}$ and Abdollah Khadivi-Khub ${ }^{2}$ \\ ${ }^{1}$ Department of Biotechnology and Physiology of Horticultural Plants, Iranian Academic Center for Education Culture and Research (ACECR), Karaj, Iran \\ ${ }^{2}$ Department of Horticultural Sciences, Faculty of Agriculture and Natural Resources, Arak University, 38156-8-8349 Arak, Iran
}

\begin{abstract}
Vegetative propagation of walnut is difficult compared with that of other fruit and nut species. The present study assessed three methods of grafting (patch, shield, and chip) at various periods of walnut growth and with different timings of grafting in walnut. Early May was the best time for grafting, at which time the highest success rate was obtained by the patch method (96\%), followed by chip-budding (75\%), while shield-grafting showed the lowest efficiency (10\%). Patch-grafting was also successful (75-80\%) in early August and moderately successful in mid-June (51-55\%), while the shield and chip methods had no success during these two times (0.00\%). Patch-grafting was more efficient and also induced better callus formation and scion growth than the other two methods. The genotypes used did not affect grafting efficiency. The best results were obtained by patch-budding in both tested genotypes. The present findings show the potential value of patch-grafting in early May as a propagation method for walnut for establishment of guidelines for propagation.
\end{abstract}

Additional key words: callus development, grafting method, grafting time, Persian walnut, propagation

\section{Introduction}

The genus Juglans includes 21 species of long lived, deciduous trees producing large, woody and shelled nuts (Manning, 1978). Persian walnut (Juglans regia L.) is one of the most economically important cultivated species for its timber and nutritious nuts (Bayazit et al., 2007). Furthermore, the plant has medicinal importance for human health which is derived from its high antioxidant capacity and $\omega-3$ fatty acid content (Ros and Matrix, 2006). The species grows in areas with a temperate climate and has been naturally distributed from east of Turkey to north of Iran, Afghanistan, Pakistan, mountains of Nepal and Central Asia (McGranahan et al., 1998).

According to the FAO statistics, Iran produces $10 \%$ of the world walnut production (Anonymous, 2010). This reflects a trend of increasing walnut production in recent years. The Iran plateau has been regarded as the site of origin of the Juglans regia species in some literature and thus, this species is named "Persian walnut" (Leslie and McGranahan, 1998). Large populations of Juglans regia exist in this region, and most of them are seedlings and notably variable in production and nut quality (Germain, 1993; Ozkan et al., 2001). Selection of promising walnut cultivars in these populations along with the market demand have increased interest in vegetative propagation of this species for better quality products (Ebrahimi et al., 2007).

Walnut trees are more difficult to graft than most of other fruit trees (Ozkan and Gumus, 2001) and poor graft success has always been considered a drawback in mass propagation of superior walnut selections (Ozkan et al., 2001). Environmental conditions during and after grafting, have a major impact on callus formation in walnut (Avanzato and Atefi, 1997). Optimally, the temperature should be maintained at about $27^{\circ} \mathrm{C}$ after indoor-grafting for better callus formation and graft success in walnut (Avanzato and Atefi, 1997; Germain, 1998). Accordingly, outdoor

\footnotetext{
*Comesponding author: znosrati@ut.ac.ir

※ Received 10 January 2014; Revised 15 August 2014; Accepted 5 September 2014

(C) 2014 Korean Society for Horticultural Science
} 
grafting is always restricted by the time of a year when such a favorable temperatures can be expected (Hartmann et al., 2001; Karadeniz, 2005).

Different techniques of grafting have been examined by several researchers to improve the temperature and humidity effects by using controlled environmental conditions (Achim and Botu, 2001; Avanzato, 2001; Ebrahimi et al., 2007; Mitrović et al., 2008; Paunović et al., 2012), however, most of these methods were unefficient, expensive, and not applicable on a large scale. Thus, existing procedures need improvement to allow efficient walnut propagation for longer periods in nontraditional months of a year. The objective of this study was to compare the efficiency of different walnut budding methods under field condition for producing grafted walnut plants at various times of a year.

\section{Materials and Methods}

This experiment was carried out at the experimental field of University of Tehran, in Karaj city in order to evaluate the effect of different budding methods and times on grafting success in walnut. The experimental site is located at an elevation of $1365 \mathrm{~m}$ a.s.l. and situated at

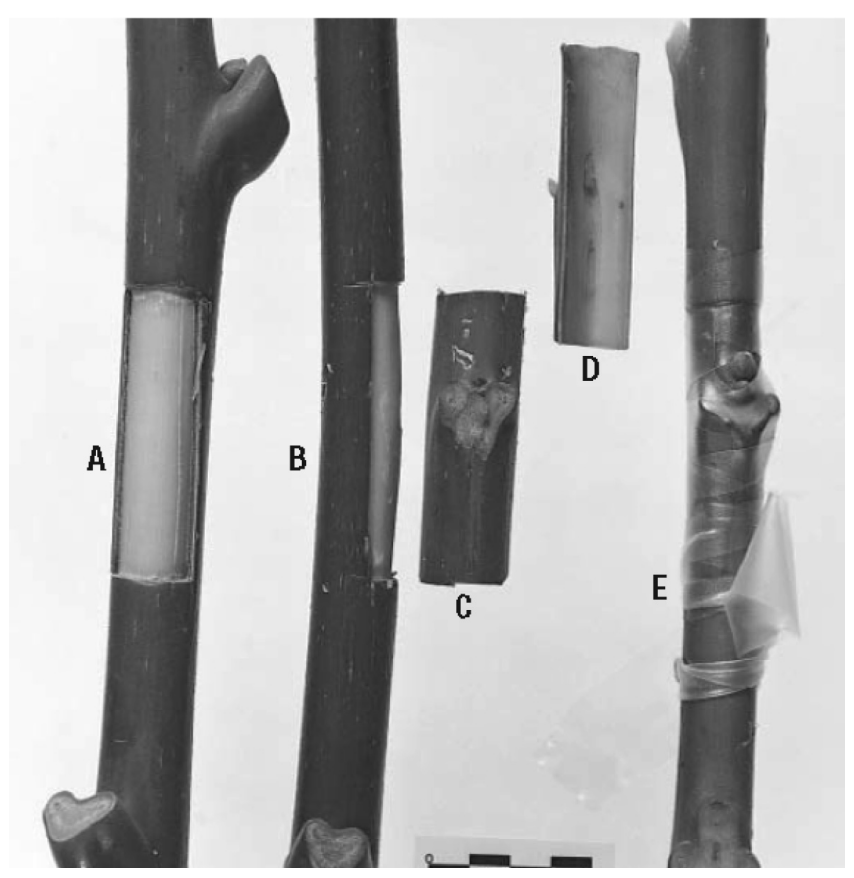

Fig. 1. Patch budding of walnut. A, Rootstock prepared for patch bud; B, Patch bud cut from selected scion; C, Patch bud outer view; D, Patch bud inner view; E, Patch bud inserted and wrapped with PVC budding tape.
N $35^{\circ} 56^{\prime}$ latitude and E $50^{\circ} 58^{\prime}$ longitude. The experiment was carried out in open field conditions with methods of patch-, shield- and chip-budding, conducted at three different dates, including early-May, mid-June and earlyAugust. Two year old seedlings raised from thick shelled nuts were used as rootstocks, which were $2-2.50 \mathrm{~cm}$ thick The scion material was taken from two domestic genotypes, i.e. Jahad1 and Jahad2. They are lateral bearing and their kernel percentage was between 55 and $60 \%$. During grafting, the top of the rootstock was cut back at three stages. Number of grafted plants per treatment was 200. Patch budding is illustrated in Fig. 1.

Since temperature and humidity have crucial effects on the healing process, they were recorded during the experiment using a maximum-minimum thermometer and a hygrometer, respectively (Fig. 2). To reduce direct light and temperature effects on the graft unions in the field, budding was done on the north-west side of the rootstocks. The top of the rootstocks were also bent on the junction portion to reduce light penetration. The experiment was laid in a Randomized Block Design (RBD). The observations were recorded on callusing rate, scion growth, and grafting success rate. Statistical analyses were conducted using the SAS (SAS Institute, Cary, NC), and means were compared by least significant difference (LSD) at 0.01 . Besides, analysis of variance (ANOVA) was performed by SAS software.

\section{Results}

The results of the effect of different methods and times of grafting are given in Tables 2 and 3. ANOVA showed significant differences between grafting methods and time treatments, while the genotypes used did not affect grafting success in all methods (Table 1). In case of Jahad1 genotype, maximum of callusing for patch-grafting was recorded in during early-May, followed by performed during early-August, while the lowest callusing for patch-grafting was observed in mid-June (Table 2). The same result was recorded in shield-grafting, followed by chip-budding done in early-May, whereas, these both grafting methods had no callusing in other two times.

Looking grafting efficiency in the genotype Jahad1, maximum grafting success rate (96\%) was observed in patch method, which was performed during early-May, following by $80.00 \%$ in early-August, while the lowest patch-grafting success was noted in mid-June (55\%). The shield- and chip- grafting were less successful regardless to the time of grafting. The growth parameters of grafted scion also showed significant differences in average scion growth 

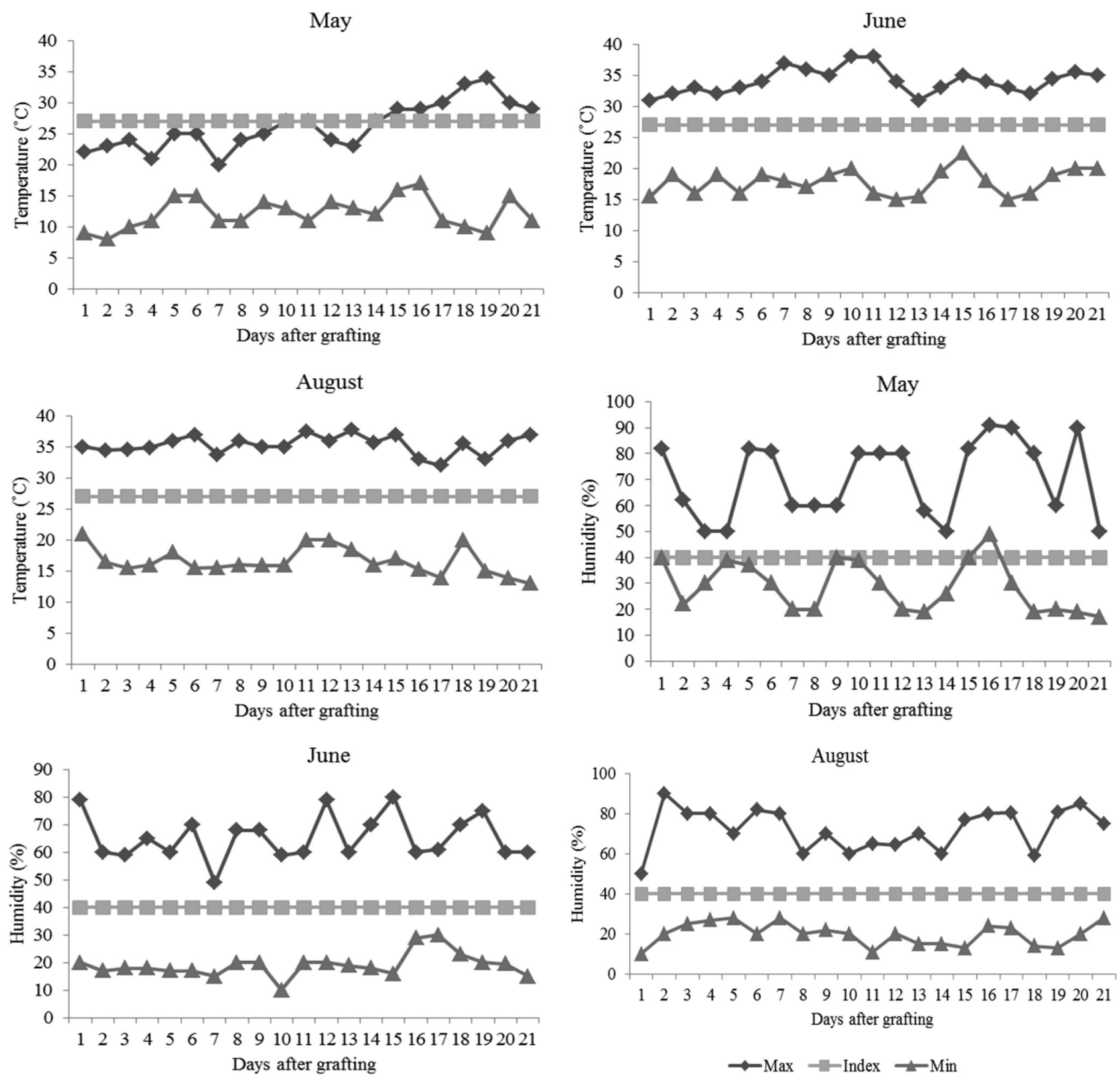

Fig. 2. Trend of daily temperatures and humidity during three weeks after budding for three times (early-May; mid-June; early-August).

when performed by different methods and during different timings of grafting. The highest scion growth was recorded for patch grafting, performed in early-May $(25.76 \mathrm{~cm})$, followed by chip-budding $(15.21 \mathrm{~cm})$, and shield-grafting $(3.47 \mathrm{~cm})$. The average scion growth for patch method was 7.03 and $4.33 \mathrm{~cm}$ after mid-June and early-August grafting, respectively (Table 2).

In a case of Jahad2 genotype, maximum callusing rate for patch-grafting was recorded during early-May, followed by early-August, while the lowest callusing for this method was recorded in mid-June. Also, this trait was recorded in case of shield grafting and followed by chip grafting done in early-May, whereas, these both grafting methods had no callusing in other two times. The early-May patch-grafting resulted also in maximum grafting success in Jahad2 genotype $(92 \%)$ followed by $75.00 \%$ performed during early-August, while the lowest patch grafting success was in mid-June (51\%). However, when the shield- and chip- 
grafting methods were done in these three times, their success was lower than patch grafting in all times. The highest scion growth in early-May was recorded for patchgrafting $(29.86 \mathrm{~cm})$, followed by chip-budding $(12.11 \mathrm{~cm})$, and shield-grafting $(1.50 \mathrm{~cm})$. The average scion growth for patch-grafting was 8.04 and $9.22 \mathrm{~cm}$ performed in midJune and early-August, respectively (Table 3).

Table 1. Combined analysis of variance for the studied treatments.

\begin{tabular}{lcccc}
\hline \multirow{2}{*}{ S.o.v. } & Df & \multicolumn{3}{c}{ Mean square of traits } \\
\cline { 3 - 5 } & & Callusing (\%) & Shoot growth $(\mathrm{cm})$ & Grafting success \\
\hline Grafting time & 2 & $338.67^{* *}$ & $92.24^{* *}$ & $63.44^{* *}$ \\
Grating method & 2 & $89.63^{* *}$ & $73.11^{* *}$ & $128.30^{* *}$ \\
Genotype & 1 & $53.00^{\mathrm{ns}}$ & $43.00^{\mathrm{ns}}$ & $99.33^{\mathrm{ns}}$ \\
Time $\times$ method & 4 & $24.68^{* *}$ & $22.88^{* *}$ & $12.86^{* *}$ \\
Time $\times$ genotype & 4 & $19.10^{\mathrm{ns}}$ & $17.60^{\mathrm{ns}}$ & $14.90^{\mathrm{ns}}$ \\
Method $\times$ genotype & 4 & $64.30^{\mathrm{ns}}$ & $80.20^{\mathrm{ns}}$ & $76.01^{\mathrm{ns}}$ \\
\hline
\end{tabular}

${ }_{\text {ns, }}^{* *}$ Non-significant and significant at the 0.01 level.

Table 2. The effect of different grafting methods and times on callus formation, scion growth and grafting success (\%) of Jahad1 genotype under field conditions.

\begin{tabular}{lcccc}
\hline Grafting time & Grafting method & Callus formation $^{\mathrm{z}}(0-3)$ & Scion growth (cm) & Grafting success (\%) \\
\hline Early-May & Patch & $3.00 \mathrm{a}$ & $25.76 \mathrm{a}$ & $96.00 \mathrm{a}$ \\
& Shield & $2.20 \mathrm{~b}$ & $3.47 \mathrm{~b}$ & $10.00 \mathrm{dc}$ \\
& Chip & $1.00 \mathrm{c}$ & $15.21 \mathrm{~b}$ & $75.00 \mathrm{ab}$ \\
Mid-June & Patch & $1.60 \mathrm{bc}$ & $7.03 \mathrm{c}$ & $55.00 \mathrm{~b}$ \\
& Shield & $0.00 \mathrm{~d}$ & $0.00 \mathrm{~d}$ & $0.00 \mathrm{dc}$ \\
& Chip & $0.00 \mathrm{~d}$ & $0.00 \mathrm{~d}$ & $0.00 \mathrm{dc}$ \\
Early-August & Patch & $2.00 \mathrm{~b}$ & $4.33 \mathrm{c}$ & $80.00 \mathrm{a}$ \\
& Shield & $0.00 \mathrm{~d}$ & $0.00 \mathrm{~d}$ & $0.00 \mathrm{dc}$ \\
& Chip & $0.00 \mathrm{~d}$ & $0.00 \mathrm{~d}$ & $0.00 \mathrm{dc}$ \\
\hline
\end{tabular}

${ }^{7}$ Callus formation rating from 1 (little callus) progressively to 3 (very good callus). Means with the same letter in each column are not significantly different. Mean separation within column by LSD at $p=0.01$.

Table 3. Influence of different grafting methods and times on callus formation, scion growth and grafting success (\%) of Jahad2 genotype under field conditions.

\begin{tabular}{|c|c|c|c|c|}
\hline Grafting time & Grafting method & Callus formation ${ }^{\mathrm{z}}(0-3)$ & Scion growth $(\mathrm{cm})$ & Grafting success (\%) \\
\hline \multirow[t]{3}{*}{ Early-May } & Patch & $2.90 \mathrm{a}$ & $29.86 \mathrm{a}$ & $92.00 \mathrm{a}$ \\
\hline & Shield & $2.50 \mathrm{~b}$ & $1.50 \mathrm{~b}$ & $7.00 \mathrm{dc}$ \\
\hline & Chip & $1.10 \mathrm{c}$ & $12.11 \mathrm{~b}$ & $70.00 \mathrm{ab}$ \\
\hline \multirow[t]{3}{*}{ Mid-June } & Patch & $1.90 \mathrm{bc}$ & $8.04 \mathrm{c}$ & $51.00 \mathrm{~b}$ \\
\hline & Shield & $0.00 \mathrm{~d}$ & $0.00 \mathrm{~d}$ & $0.00 \mathrm{dc}$ \\
\hline & Chip & $0.00 \mathrm{~d}$ & $0.00 \mathrm{~d}$ & $0.00 \mathrm{dc}$ \\
\hline \multirow[t]{3}{*}{ Early-August } & Patch & $2.40 \mathrm{~b}$ & $9.22 \mathrm{c}$ & $75.00 \mathrm{a}$ \\
\hline & Shield & $0.00 \mathrm{~d}$ & $0.00 \mathrm{~d}$ & $0.00 \mathrm{dc}$ \\
\hline & Chip & $0.00 \mathrm{~d}$ & $0.00 \mathrm{~d}$ & $0.00 \mathrm{dc}$ \\
\hline
\end{tabular}

${ }^{\bar{z}}$ Callus formation rating from 1 (little callus) progressively to 3 (very good callus). Means with the same letter in each column are not significantly different. Mean separation within column by LSD at $p=0.01$. 


\section{Discussion}

The results obtained suggested that the differences between studied grafting methods and different time treatments in terms of the parameters tested are statistically significant. The highest callusing rate, which was observed in early-May in all of the studied methods, might be due to favorable relative humidity at that time. These findings are in agreement with those of Rongting and Pingai (1993) and Ebrahimi et al. (2007) who observed that maximum of callusing rate was recorded when relative humidity was $55-60 \%$. Moreover, all of the grafting methods done during early-May, were more successful than other two terms in both genotypes, and the patch method showed the highest graft take success. The patch method also had better grafting success rate in early-August and mid-June than shield-grafting and chipbudding, respectively. The maximum grafting success in patch grafting during early-May and then early-August might be due to the fact that the favorable temperature $\left(20-30^{\circ} \mathrm{C}\right.$ daily and $8-15^{\circ} \mathrm{C}$ nightly) and relative humidity at these times of grafting and rapid sap flow in rootstock and scion favoured the healing process and established the continuity of cambial and vascular tissues for the graft take. These observations are in agreement with those of Papalexandris (1982) who reported that maximum take was recorded in patch-grafting when temperature was $20-30^{\circ} \mathrm{C}$. The lower success rate in patch-grafting and the other methods in mid-June might be due to the low temperature and relative humidity at the time of grafting. In the present study, patch grafting of Jahad1 and Jahad2 yielded 96 and $92 \%$ success rate, respectively, which is more than the ones reported elsewhere (Atefi and Mostafavi, 1987; Gandev, 2007; Kuden and Kaska, 1997).

Chip-budding, one of the main methods for walnut's vegetative propagation, showed high success rate $(70-75 \%)$ in early-May and had no success in mid-June and earlyAugust. Rezaee et al. (2007) reported low success rate for chip-budding studied at three different terms, while Ebrahimi et al (2007) reported about 19 and 10\% successful after greenhouse and field grafting, respectively. Furthermore, shield-grafting had the lowest efficiency in early-May (7-10\%) and no success in mid-June and early-August. Gautman (1990) and Zima (1992) reported about 10 and $14.6 \%$ of success rate for shield-grafting, respectively. The comparatively lower percentage of success in shield grafting method in comparison to the patch and chip graftings might be due to the fact that the connection between rootstock and scion skins is weak (Hartmann et al., 2001) and because of high sap flow and high skin thickness (Atefi and Mostafavi, 1987), in accordance with results of Ebrahimi et al. (2008).

The present results suggest that patch-grafting induces better callusing, scion growth and bud-take as compared with shield-grafting and chip-budding, especially in earlyMay. Therefore, we can recommend patch-grafting method, conducted in early-May to be implemented as a common method of commercial walnut propagation. This technique is also economically interesting and promising for new areas of walnut growing, and for propagation during nontraditional months of the year.

\section{Literature Cited}

Achim, G. and I. Botu. 2001. Results in walnut propagation using different methods. Acta Hort. 544:503-509.

Anonymous. 2010. Walnut trade statistics. FAO statistical data. Food and Agricultural Organization of United Nations, Roma.

Atefi, J. and M. Mostafavi. 1987. Patch grafting in walnut. J. Seed Plant 23:30-34.

Avanzato, D. 2001. Effect of different hygro-thermic environments on growth of potted walnut grafted seedlings. Acta Hort. 544:459-464.

Avanzato, D. and J. Atefi. 1997. Walnut grafting by heating the graft-point directly in the field. Walnut grafting by heating the graft-point directly in the field. Acta Hort. 442:291-294.

Bayazit, S., Kazan K., S. Gülbitti, V. Çevik, H. Ayanoglu, and A. Ergül. 2007. AFLP analysis of genetic diversity in low chill requiring walnut (Juglans regia L.) genotypes from Hatay, Turkey. Sci. Hortic. 111:394-398.

Ebrahimi, A., K. Vahdati, and E. Fallahi. 2007. Improved success of persian walnut grafting under environmentally controlled conditions. Int. J. Fr. Sci. 6:3-12.

Ebrahimi, A., R. Fatahi, and K. Vahdati. 2008. The effects of environmental conditions, method and time on the success of budding in walnut. J. Hortic. Sci. 39:10-25.

Gandev, S. 2007. Budding and grafting of the walnut (Juglans regia L.) and their effectiveness in Bulgaria. Bulg. J. Agri. Sci. 13:683-689.

Gautman, D.R. 1990. Studies on the winter and summer vegetative propagation techniques of walnut (Juglans regia L.). Acta Hort. 284:27-31.

Germain, E. 1993. The Persian walnut in Iran. Nucis Nswl. 1:5-6.

Germain, E. 1998. Production and economics of nut crops. Advanced course, May 18-29, Adana, Turkey.

Hartmann, H.T., D.E. Kester, F.T. Davies, and R.L. Geneve. 2001. Plant propagation: Principles and practices. 7 th ed. Prentice Hall International Inc., NJ.

Karadeniz, T. 2005. Relationships between graft success and climatic values in walnut (Juglans regia L.). J. Central European Agr. 6:631-634. 
Kuden, A. and N. Kaska. 1997. Studies on the patch budding of walnuts in different budding periods under subtropical conditions. Acta Hort. 442:299-301.

Leslie, C.A. and G.H. McGranahan. 1998. The origin of walnut, p. 3-7. In: D. Ramos (ed.). Walnut production manual. University of California, DANR Publ., Davis.

Manning, W.E. 1978. The classification within the Juglandaceae. Ann .Missouri Bot. Garden 65:1058-1087.

McGranahan, G.H., A. Charles, C.A. Leslie, H.A. Philips, and A. Dandaker. 1998. Walnut propagation, p. 71-83. In: D. Romos (ed). Walnut production manual. Univ of California, DANR Publ., Davis

Mitrović, M., R. Miletić, M. Lukić, M. Blagojević, and M. Rakićević. 2008. Impact of rootstock on callus formation in walnut grafted in room conditions. J. Pomol. 42:43-47.

Ozkan, Y. and A. Gumus. 2001. Effects of different applications on grafting under controlled conditions of walnut. Acta Hort. 544:515-520.

Ozkan, Y., Y. Edizer, and Y. Akca. 2001. A study on propagation with patch budding of some walnut (Juglans regia L.) cultivars. Acta Hort. 544:521-526.

Papalexandris, K.H. 1982. Grafting of walnut trees with patch budding. Agris 4:1986-1988.

Paunović, M., R. Miletić, M. Mitrović, and D. Janković. 2012. Graft-take success in walnut under controlled conditions and plant development in the nursery. Not. Bot. Horti. Agrobo. 40:170-176.

Rezaee, R., V. Grigoorian, K. Vahdati, and M. Valizadeh. 2007. Effects on walnut seedling vigor on root pressure, grafting success and scion growth. Iran. J. Hort. Sci. Tech. 8:21-30.

Rongting, X. and D. Pinghai. 1993. A study on the uniting process of walnut grafting and the factors affecting. Acta Hort. 311: 160-170.

Ros, E. and J. Mataix. 2006. Fatty acid composition of nutsimplications for cardiovascular health. Brit. J. Nutr. 96:29-35.

Zima, A.I. 1992. The effect of budding method on the growth and production of walnut trees. Acta Hort. 237:63-68. 